\title{
Residual da adubação fosfatada e efeito da inoculação com Azospirillum brasilense em milho verão consorciado com gramínea em região de cerrado
}

\author{
Residual phosphate fertilization and the effect of inoculation with Azospirillum brasilense on \\ summer corn intercropped with grass in a cerrado region \\ La fertilización fosfatada residual y el efecto de la inoculación con Azospirillum brasilense en el \\ maíz de verano intercalado con hierba en una región de cerrado
}

Recebido: 25/01/2022 | Revisado: 02/02/2022 | Aceito: 09/02/2022 | Publicado: 13/02/2022

\author{
Lourdes Dickmann \\ ORCID: https://orcid.org/0000-0002-9608-6640 \\ Universidade Estadual Paulista Júlio de Mesquita Filho, Brasil \\ E-mail: lourdesdickmann@hotmail.com \\ Allan Hisashi Nakao \\ ORCID: https://orcid.org/0000-0002-2465-1663 \\ Universidade Estadual Paulista Júlio de Mesquita Filho, Brasil \\ E-mail: allanhisashinakao@gmail.com \\ Viviane Cristina Modesto \\ ORCID: https://orcid.org/0000-0002-9467-9346 \\ Universidade Estadual Paulista Júlio de Mesquita Filho, Brasil \\ E-mail: vivimodesto12@gmail.com \\ Izabela Rodrigues Sanches \\ ORCID: https://orcid.org/0000-0003-0259-7405 \\ Universidade Estadual Paulista Júlio de Mesquita Filho, Brasil \\ E-mail: izabelars.agr@gmail.com \\ Marcelo Andreotti \\ ORCID: https://orcid.org/0000-0001-5468-0986 \\ Universidade Estadual Paulista Júlio de Mesquita Filho, Brasil \\ E-mail: marcelo.andreotti@unesp.br
}

\begin{abstract}
Resumo
A crescente necessidade de ter sistemas de produção agrícolas sustentáveis, faz com que o agronegócio busque estratégias para atender o aumento da demanda por matérias-primas animais e vegetais, impulsionando o maior uso da terra. O trabalho teve como objetivoavaliar o efeito residual da adubação fosfatada sobre o crescimento e produtividade do milho com e sem inoculação de A. brasilense e da produção de massa seca do capim-marandu em consórcio. $\mathrm{O}$ experimento foi desenvolvido em área exprimental pertencente à FE/UNESP, em Selvíria, MS. O solo foi classificado como Latossolo Vermelho distrófico típico argiloso. Os experimentos de consórcio de milho com U. brizantha cv. Marandu (capim-marandu) foram desenvolvidos nas safras de 2013/14 e 2015/16. O delineamento experimental foi o de blocos casualizados, com quatro repetições, em esquema fatorial 5 x 2. Avaliou-se o efeito residual de níveis de adubação fosfatada $(0 ; 30 ; 60 ; 120$ e $240 \mathrm{~kg}$ ha-1 de P2O5), aplicados a lanço na semeadura da aveia preta em junho de 2013, com ou sem a inoculação das sementes de milho com A. brasilense. De acordo com os resultados obtidos, a inoculação das sementes de milho por A. brasilense e a adubação fosfatada residual não resultaram em efeitos positivos sobre o crescimento, componentes da produção e produtividade de grãos de milho consorciado com capim-marandu. Por sua vez, o capim-marandu foi beneficiado pela inoculação, nas sementes de milho, produzindo maior massa de parte aérea em áreas inoculadas com A. brasilense.
\end{abstract}

Palavras-chave: Zea mays; Capim; Consórcio; Palhada; Sistema de plantio direto.

\begin{abstract}
The growing need to have sustainable agricultural production systems makes agribusiness seek strategies to meet the increased demand for animal and vegetable raw materials, driving greater land use. The objective of this study was to evaluate the residual effect of phosphate fertilization on the growth and productivity of corn with and without inoculation of A. brasilense and on the dry mass production of marandu grass in a intercrop. The experiment was developed in an experimental area belonging to FE/UNESP, in Selvíria, MS. The soil was classified as Oxysol. The experiments of corn intercropping with U. brizantha cv. Marandu (marandu grass) were developed in 2013/14 and 2015/16 crops. The experimental design was randomized blocks, with four repetitions, in a 5 x 2 factorial scheme. The residual effect of phosphate fertilization levels $(0 ; 30 ; 60 ; 120$ and $240 \mathrm{~kg}$ ha-1 of P2O5), applied by sowing black oats in June 2013, was evaluated, with or without inoculation of corn seeds with A. brasilense. According to the results
\end{abstract}


obtained, the inoculation of corn seed with A. brasilense and residual phosphate fertilization did not result in positive effects on growth, yield components and grain yield of corn intercropped with marandu grass; marandu grass, in turn, benefited from inoculation in corn seed, producing greater aerial part mass in areas inoculated with A. brasilense.

Keywords: Zea mays; Grass; Consortium; Straw; No-till system.

\section{Resumen}

La creciente necesidad de contar con sistemas de producción agrícola sostenibles, hace que la agroindustria busque estrategias para satisfacer la creciente demanda de materias primas animales y vegetales, impulsando el mayor uso de la tierra. El objetivo de este trabajo fue evaluar el efecto residual de la fertilización fosfatada sobre el crecimiento y la productividad del maíz con y sin inoculación de A. brasilense y la producción de masa seca del pasto marandú en intercultivo. El experimento se desarrolló en un área experimental perteneciente a FE/UNESP, en Selvíria, MS. El suelo fue clasificado como típicamente distrófico rojizo arcilloso LATOSSOLO VERMELHO. Los experimentos de cultivo intercalado de maíz con U. brizantha cv. Marandu (hierba marandú) se desarrollaron en las cosechas 2013/14 y 2015/16. El diseño experimental fue el de bloques al azar, con cuatro repeticiones, en un esquema factorial de $5 \times 2$. Se evaluó el efecto residual de los niveles de fertilizantes fosfatados $(0 ; 30 ; 60 ; 120$ y $240 \mathrm{~kg}$ ha-1 de P2O5), aplicados en la siembra de avena negra en junio de 2013, con o sin inoculación de semillas de maíz con A. brasilense. De acuerdo con los resultados obtenidos, la inoculación de la semilla de maíz por A. brasilense y la fertilización fosfatada residual no resultaron en efectos positivos sobre el crecimiento, los componentes de la producción y el rendimiento de grano del maíz intercalado con el pasto marandú; el pasto marandú, por su parte, se vio beneficiado por la inoculación, en la semilla de maíz, produciendo mayor masa de parte aérea en las áreas inoculadas con A. brasilense.

Palabras clave: Zea mays; Hierba; Cultivo intercalado; Paja; Sistema de cultivo sin labranza.

\section{Introdução}

A crescente necessidade de ter sistemas de produção agrícolas sustentáveis, faz com que o agronegócio busque estratégias para atender o aumento da demanda por matérias-primas animais e vegetais, impulsionando o maior uso da terra. Nesse contexto, Gasparini et al. (2017), citam que é possível conciliar a expansão da agricultura com o uso mais eficiente dos recursos naturais, incorporando tecnologia.

Nesse caminho, os Sistemas Integrados de Produção Agropecuária (SIPAs) no Brasil, tem crescido exponencialmente devido à pressão social em relação à sustentabilidade e a demanda por altas produtividades com menores custos. Estes sistemas assumem grande importância por constituir uma maneira racional de cultivo, por atenuar problemas com erosão, e perdas de nutrientes e desequilíbrio da macro e micro fauna das áreas agrícolas (Carvalho, et al., 2015; Tiecher, et al., 2017).

Nesse contexto, o sistema plantio direto (SPD), desde que manejado seguindo seus princípios básicos como a manutenção permanente da cobertura e mínimo revolvimento do solo, atrelado à rotação de culturas diversificadas, traz alterações positivas para as propriedades físicas, químicas e biológicas do solo (Carvalho, et al., 2015). Nesta mesma linha de pensamento, Nascente e Crusciol (2012) afirmam que dentre os sistemas que integram o SPD, o cultivo consorciado de culturas graníferas (como o milho, soja, arroz e sorgo) com forrageiras tropicais é uma ótima opção para produção de palhada residual.

No consórcio, a forrageira pode ser utilizada para a alimentação animal, no período de entressafra, ou como palha, para continuidade do SPD. Nesta modalidade, o mais comum é utilizar o milho em consórcio com plantas do gênero Urochloa (Syn. Brachiaria) (Concenço, et al., 2012; Sereia, et al., 2012; Batista, et al., 2011), que proporciona maior produção de palhada e com isso melhor cobertura de solo, situação favorável ao SPD, e em consequência, gera maiores produtividades nas culturas subsequentes (Chioderoli et al., 2010).

Dentre os nutrientes que mais limitam a produção de grãos no Brasil, em especial as gramíneas, destaca-se o fósforo (P), principalmente nas regiões de Cerrado, onde se encontram os Latossolos, que pela sua constituição oxídica da fração argila apresentam alta complexação do nutriente e, portanto, torna-se fator de restrição para a produção das culturas agrícolas (Valderrama, et al., 2011).

Ainda que as exigências em fósforo sejam, em quantidade, bem menores quando comparado aos outros macronutrientes, as doses normalmente recomendadas são altas, em função da baixa eficiência de aproveitamento pela cultura, decorrente da alta capacidade de adsorção do fósforo adicionado ao solo, reduzindo sua disponibilidade às plantas (Conceição, et al., 2012). 
Com a crescente busca por sustentabilidade nos sistemas agrícolas de produção, e os elevados gastos com insumos agrícolas, alguns autores tem apresentado como alternativa para economia de fertilizantes, o uso de bactérias promotoras de crescimento vegetal, as quais visam a redução na adubação e aumento da eficiência na utilização dos nutrientes (Reis Júnior, et al., 2008; Bergamaschi, 2006). Assim, cresce o interesse pelo uso de inoculantes que em sua composição possuem bactérias promotoras de crescimento de plantas, principalmente pela busca de uma agricultura sustentável com menor poluição ambiental, aliado a redução dos custos de produção (Hungria, et al., 2010).

Novakowiski et al. (2011) relataram que uma das alternativas para se obter aumento da produção agrícola, com custos menores e sem interferir negativamente no ambiente, seria aliar o potencial genético das plantas com os recursos biológicos do solo, como as bactérias diazotróficas, em especial as do gênero Azospirillum.

Assim objetivou-se nesse trabalho, avaliar o efeito residual da adubação fosfatada e da decomposição da palhada da aveia preta sobre o crescimento e produtividade do milho, em sucessão, com e sem inoculação pelo A. brasilense e da produção de massa seca do capim-marandu (U. brizantha) em consórcio no Cerrado.

\section{Metodologia}

\subsection{Localização, histórico e caracterização da área experimental}

O experimento foi desenvolvido na Fazenda de Ensino, Pesquisa e Extensão (FEPE) - Setor de Produção Vegetal, pertencente à Faculdade de Engenharia de Ilha Solteira (FE/UNESP), localizada no município de Selvíria, MS, com as coordenadas geográficas $\left(20^{\circ} 18^{\prime} \mathrm{S}\right.$ e $51^{\circ} 22^{\prime} \mathrm{W}$, e altitude de aproximadamente $\left.370 \mathrm{~m}\right)$.

O relevo é caracterizado como moderadamente plano, tendo sido o solo classificado como LATOSSOLO VERMELHO distrófico típico argiloso (SANTOS et al., 2018). O tipo climático é Aw, segundo classificação de Köppen, caracterizado como tropical úmido com estação chuvosa no verão e seca no inverno. A precipitação média anual é de $1370 \mathrm{~mm}$ e a temperatura média de $23,5^{\circ} \mathrm{C}$ (Hernandez et al., 1995).

A pesquisa iniciou-se no ano de 2013 numa área onde o solo estava sendo cultivado com culturas anuais em SPD há 10 anos. Durante a condução do experimento houve uma sequência de culturas, às quais fizeram parte deste ciclo, o consórcio de milho com U. brizantha cv. Marandu (capim-marandu) nos safras de 2013/14 e 2015/16. Durante a condução do experimento foram coletados, junto à estação meteorológica situada na FEPE da FEIS/UNESP, os dados diários referentes às temperaturas máxima, média e mínima e precipitação pluvial (Figura 1). 
Figura 1 - Dados climáticos coletados na estação meteorológica da FEPE, durante o período de condução dos experimentos. Selvíria/MS, 2013/2014/2015/2016.

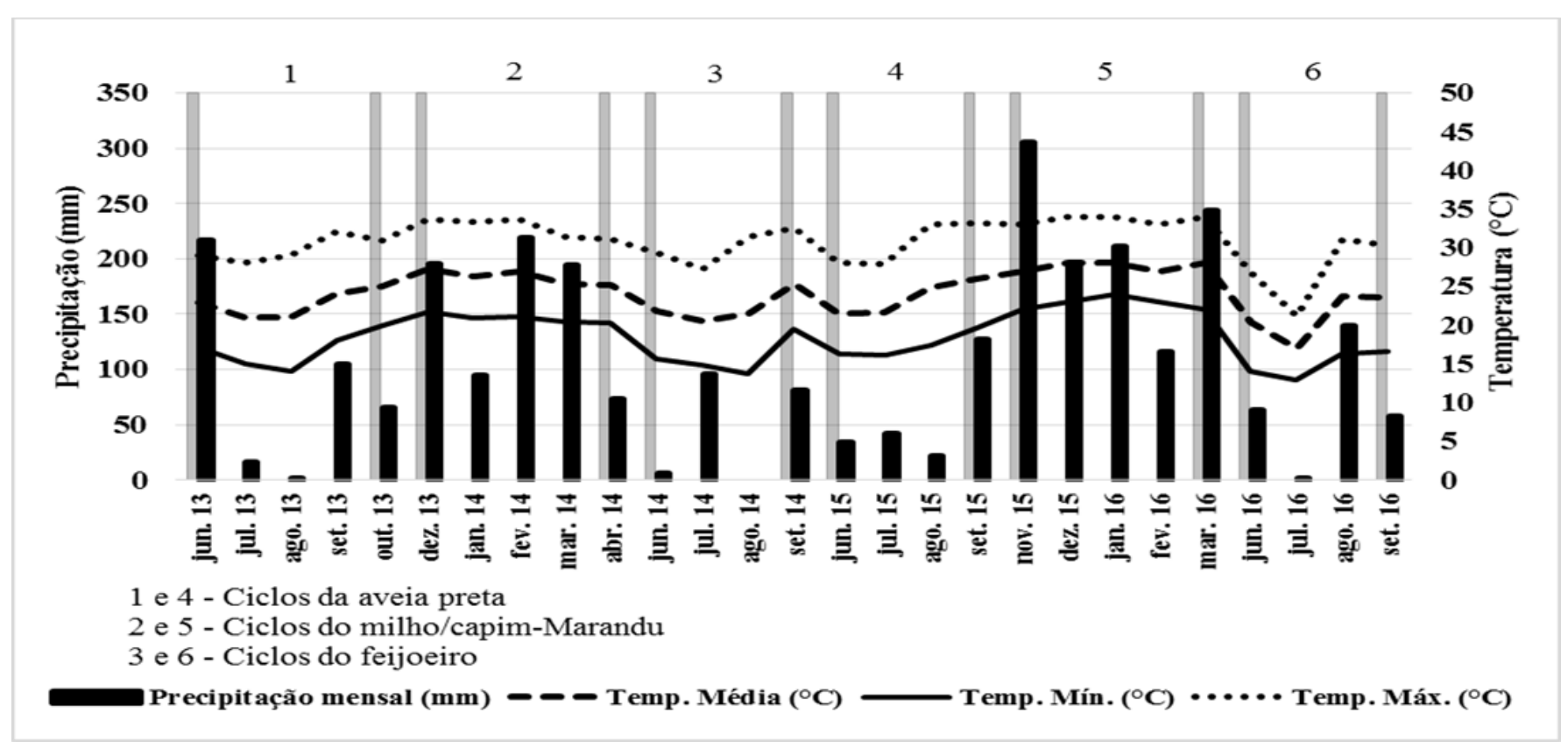

Fonte: Estação meteorológica - Fazenda de Ensino, Pesquisa e Extensão da FE/UNESP. Selvíria, MS.

Com o intuito de efetuar caracterizações química do solo efetuou-se o levantamento da fertilidade no início do experimento, na camada de $0-0,20 \mathrm{~m}$, segundo metodologia proposta por Raij et al. (2001). Os resultados obtidos foram: pH 5,0 (em CaCl2); $25 \mathrm{~g} \mathrm{dm}^{-3}$ de matéria orgânica (MO); $16 \mathrm{mg} \mathrm{dm-3} \mathrm{de} \mathrm{P} \mathrm{(fósforo-resina);} \mathrm{19;} 2,2$ e 14 mmol $\mathrm{dm}^{-3}$,

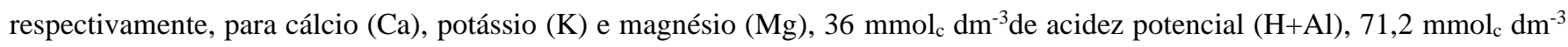
de capacidade de troca catiônica (CTC), e 49\% de saturação por bases (V \%).

Em abril de 2013, com base nos resultados da análise química do solo e com a finalidade de elevar a saturação por bases a 70\%, realizou-se a aplicação de calcário dolomítico (PRNT de 87\%) a lanço e em área total, na dose de 1,7 t ha-1 (superficial e sem incorporação). Seguiu-se este procedimento em função do histórico de 10 anos em SPD e do elevado teor de argila do solo, o que lhe confere ao alto poder tampão.

Após os cultivos de aveia preta em 2013 e 2015, para caracterização da fertilidade do solo e recomendação da adubação do milho, realizou-se levantamentos seguindo a metodologia proposta por Raij et al. (2001), com coletas por parcela, na camada 0 a 0,20 m. Para tanto, foram coletadas (07/11/2013 e 01/10/2015) dez amostras simples por parcela, com auxílio de um trado de rosca, das quais gerou-se amostras compostas para secagem e análise química. Os resultados obtidos foram baseados na média de todas as parcelas. No ano de 2013: $\mathrm{pH}$ em $\mathrm{CaCl}_{2}$ de 5,3; matéria orgânica de $22 \mathrm{~g} \mathrm{dm}^{-3}$; P (resina) $25 \mathrm{mg} \mathrm{dm-3;} 32 ; 3,2$ e 24 $\mathrm{mmol}_{\mathrm{c}} \mathrm{dm}^{-3}$, respectivamente, para cálcio, potássio e magnésio, $31 \mathrm{mmolc} \mathrm{dm}^{-3}$ de acidez potencial $(\mathrm{H}+\mathrm{Al}), 90,1 \mathrm{mmol}_{\mathrm{c}} \mathrm{dm}{ }^{3} \mathrm{de}^{-}$ CTC, com saturação por bases de 64\%. Enquanto que para 2015 obteve-se: $\mathrm{pH}$ em $\mathrm{CaCl}_{2}$ de 5,4; matéria orgânica de $22 \mathrm{~g}$ dm ${ }^{-3}$; $\mathrm{P}$ (resina) $19 \mathrm{mg} \mathrm{dm}^{-3} ; 27 ; 2,4$ e $20 \mathrm{mmol}_{\mathrm{c}} \mathrm{dm}^{-3}$, respectivamente, para cálcio, potássio e magnésio, $28 \mathrm{mmol}_{\mathrm{c}} \mathrm{dm}^{-3} \mathrm{de}_{\mathrm{acidez}}$ potencial $(\mathrm{H}+\mathrm{Al}), 77,0 \mathrm{mmol}_{\mathrm{c}} \mathrm{dm}^{-3}$ de CTC, com saturação por bases de $63 \%$.

O estudo compreendeu dos consórcios do milho com capim-Marandu, os quais foram conduzidos em dois anos de cultivo, ocorridos nas safras 2013/14 e 2015/16, sob a palhada da cultura de aveia preta implantada em antecessão.

\subsection{Delineamento experimental e tratamentos}

O delineamento experimental utilizado durante a condução dos dois anos de cultivo foi o de blocos casualizados, com 
quatro repetições, em esquema fatorial 5 × 2, ou seja, avaliou-se o efeito residual da adubação fosfatada nas cinco doses de fósforo $\left(0 ; 30 ; 60 ; 120\right.$ e $240 \mathrm{~kg}$ ha-1 de $\left.\mathrm{P}_{2} \mathrm{O}_{5}\right)$, aplicados a lanço na semeadura da aveia preta em junho de 2013, com ou sem a inoculação das sementes de milho com a bactéria A. brasilense (estirpes AbV5 e AbV6 (garantia de 2x108 UFC mL-1)) em 2013 e 2015 fornecida via inoculante líquido para gramíneas, na dose comercial de $100 \mathrm{~mL}$ para $25 \mathrm{~kg}$ de sementes. A inoculação das sementes foi realizada momentos antes da semeadura, à sombra, as quais também foram tratadas com defensivos conforme o padrão comercial da Empresa fornecedora das sementes do híbrido utilizado.

Cada unidade experimental (parcela) constituiu-se de $4,4 \mathrm{~m}$ de largura e $10 \mathrm{~m}$ de comprimento, perfazendo $44 \mathrm{~m}^{2}$. $\mathrm{O}$ milho foi consorciado com a Urochloa brizantha cv. Marandu (capim-marandu), sendo semeada conjuntamente nas entrelinhas do milho.

\subsection{Preparo da área experimental, instalação e condução dos experimentos}

Antes da instalação do consórcio do milho com capim-marandu no ano de 2013, as plantas daninhas foram controladas, em 04/10/2013, com uso do herbicida glyphosate (1,44 $\mathrm{kg} \mathrm{ha}^{-1}$ do ingrediente ativo (i.a.)). Não houve a necessidade de utilização do triturador horizontal de resíduos vegetais e de aplicações posteriores de herbicidas antes da semeadura. Para a implantação do consórcio em 2015, também foi realizado o controle das plantas daninhas, em 12/11/2015, com a aplicação dos herbicidas carfentrazona-etílica (20 $\mathrm{g} \mathrm{ha}^{-1}$ do i.a. $)+$ glyphosate (1,56 $\mathrm{kg} \mathrm{ha}^{-1}$ do i.a. $)+$ haloxifope-p-metílico ( $60 \mathrm{~g} \mathrm{ha}^{-1}$ do i.a.).

A cultura do milho foi semeada sob a palhada da aveia preta antecessora nos dois cultivos. Efetuou-se a semeadura do milho híbrido precoce AG 8088 YG em 04/12/2013, e para o segundo ano de consórcio, utilizou-se o híbrido precoce DKB 350 PRO, realizando-se a semeadura em 17/11/2015. Em ambos os cultivos, se utilizou uma semeadora-adubadora de mecanismo sulcador do tipo haste (facão) para SPD, depositando as sementes na profundidade de 0,05 m, com espaçamento entrelinhas de $0,90 \mathrm{~m}$, objetivando-se atingir um estande final de 60000 plantas ha- 1 .

A semeadura do capim-marandu, em ambos os anos dos consórcios, foi realizada simultaneamente à do milho, utilizando outra semeadora-adubadora com mecanismo sulcador do tipo disco duplo desencontrado para SPD, onde foram semeadas duas linhas da forrageira nas entrelinhas da cultura do milho. As sementes foram acondicionadas no compartimento do adubo da semeadora e depositadas abaixo das sementes de milho, na profundidade de $0,06 \mathrm{~m}$, espaçadas em $0,34 \mathrm{~m}$ entre linhas, utilizando-se aproximadamente $7 \mathrm{~kg} \mathrm{ha}^{-1}$ de sementes com valor cultural (VC) de $76 \%$. As sementes de capim foram depositadas abaixo das sementes de milho, com o objetivo de atrasar a sua emergência em relação à do milho, e reduzir a provável competição inicial entre as espécies (Kluthcouski et al., 2000).

$\mathrm{Na}$ adubação de semeadura para o cultivo de 2013 foram adicionados $200 \mathrm{~kg} \mathrm{ha}^{-1}$ do formulado 20-0-20, enquanto que em 2015 foram utilizados $400 \mathrm{~kg} \mathrm{ha}^{-1}$ também do formulado 20-0-20. Em ambos os consórcios quando a cultura do milho atingiu o estádio fenológico V6 (seis folhas totalmente desenvolvidas), procedeu-se a adubação de cobertura de forma manual e próximo as linhas do milho, com aplicação de $120 \mathrm{~kg} \mathrm{ha}^{-1}$ de N, na forma de sulfato de amônio (06/01/2014 e 09/12/2015). Tanto as adubações de semeadura quanto as de cobertura em ambos os anos de cultivo seguiram as recomendações de Cantarella, Raij e Camargo (1997).

\subsection{Avaliações realizadas e análises}

Para realização das avaliações e análises, seguiu-se os mesmos procedimentos em ambos os cultivos (2013/2014 e 2015/2016). Nos dias 07/03/2014 e 03/02/2016, efetuou-se a avaliação dos atributos morfológicos (diâmetro basal do colmo, altura da planta e da inserção da espiga principal) e os componentes da produção (população de plantas e número de espigas ha1). A altura das plantas (ALTP) e da inserção das espigas principais (AIE) foram determinadas mediante mensuração, com régua graduada em centímetros, da distância entre o colo da planta e a inserção do pendão floral e a distância entre o colo da planta e 
a espiga principal, respectivamente. O diâmetro basal do colmo (DBC) foi determinado no segundo entrenó acima do solo com o auxílio de paquímetro. Estas determinações foram efetuadas em 10 plantas aleatoriamente dentro da área útil de cada unidade experimental. A contagem do número de plantas e do número de espigas foi efetuada na área útil da parcela (duas linhas centrais de $10 \mathrm{~m}$ de comprimento, desprezando-se um metro em ambas as extremidades) em cada unidade experimental, transformando os resultados em hectare.

Na ocasião da colheita do milho, em 02/04/2014 e em 17/03/2016, foram coletadas dez espigas aleatoriamente em cada unidade experimental, das quais foram efetuadas as avaliações dos demais componentes da produção (comprimento de espiga, número de fileiras de grãos/espiga, de grãos/fileira, de grãos/espiga, massa de grãos/espiga e de 100 grãos).

Para determinar o comprimento da espiga (CE) utilizou-se régua graduada em centímetros. Posteriormente, foram avaliados o número de fileiras de grãos por espiga (NFE) e o número de grãos por fileira (NGF). O número de grãos por espiga (NGE) foi calculado multiplicando-se o NF pelo NGF, em dez espigas por parcela. A massa de 100 grãos (M100) foi determinada pela média dos grãos de quatro amostras de 100 grãos, e os resultados foram corrigidos para o teor de 13\% de umidade (base úmida).

Na mesma data da colheita do milho, avaliou-se a produtividade de grãos (PROD), onde para tal determinação, coletouse manualmente todas as espigas das plantas contidas na área útil da parcela (duas linhas centrais com $8 \mathrm{~m}$ de comprimento). Em seguida, as espigas foram debulhadas mecanicamente, pesando-se os grãos, calculando-se a produtividade da parcela, extrapolada para kg ha-1 e corrigida para as condições de 13\% de umidade (base úmida).

Em ambas as safras foi determinada a produtividade de massa seca do capim-marandu (03/04/2014 e 18/03/2016). Iniciou-se as avaliações com coleta de 3 repetições de $1 \mathrm{~m}^{2}$ (quadrado de metal de 1,0 x 1,0 m) da parcela (altura de corte de $0,05 \mathrm{~m}$ ) do capim-marandu, utilizando-se a foice para o corte. O material vegetal cortado foi pesado, em seguida separado em subamostras, colocado em estufas de ventilação forçada de ar a $65^{\circ} \mathrm{C}$ por 72 horas para depois ser pesado novamente e efetuar os cálculos de quantificação da produtividade de matéria seca (PMS extrapolada para kg ha-1.

Após 60 dias a colheita do milho (período simulando a vedação do pasto) em 2013/14 e 2015/16, respectivamente, foram efetuadas amostragens para determinação da produtividade de matéria seca da parte aérea do capim-marandu. Para tanto, foram coletadas 3 repetições de $1 \mathrm{~m}^{2}$ (quadrado de metal de 1,0 x 1,0 m), da parcela adotando-se como altura de corte 0,30 m, simulando o pastejo. $\mathrm{O}$ material vegetal cortado foi pesado e separado em subamostras, em seguida colocado em estufa de ventilação forçada de ar a $65^{\circ} \mathrm{C}$ por 72 horas, pesados novamente ao retirar da estufa para assim realizar os cálculos da quantificação da PMS (extrapolada para kg ha-1).

\subsection{Análise estatística}

Os resultados obtidos, em ambas as safras, foram submetidos à análise de variância pelo teste $\mathrm{F}(\mathrm{P}<0,05)$. $\mathrm{O}$ efeito de inoculação ou não com A. brasilense foram comparados pelo teste $t$ (Student) $(\mathrm{P}<0,05)$. Enquanto que o efeito da adubação fosfatada residual foi avaliado por análise de regressão, adotando-se nos modelos significativos, o de equação com maior coeficiente de determinação $\left(\mathrm{R}^{2}\right)(\mathrm{P}<0,05)$. As análises estatísticas foram realizadas utilizando o software SISVAR® (Ferreira, 2011).

\section{Resultados e Discussão}

A inoculação das sementes de milho com A. brasilense promoveu alterações na altura de planta (AP) e altura de inserção da espiga (AIE) apenas no milho em consórcio da safra 2013/14 (Tabela 1). Deste modo, valores superiores de 258 e $125 \mathrm{~cm}$ foram obtidos para AP e AIE, respectivamente. Resultados distintos foram obtidos por Cavallet et al. (2000) e Galindo (2015), em que a inoculação por A. brasilense não influenciou tais atributos morfológicos. Os resultados corroboram aos constatados 
por Costa et al. (2015), que estudando a inoculação de A. brasilense na cultura do milho de segunda safra, relataram aumento de 10\% na altura das plantas com sementes inoculadas. Também Kappes et al. (2013), avaliando a inoculação com bactérias diazotróficas na cultura do milho, verificaram aumento na altura média das plantas inoculadas e na produtividade de grãos do milho.

Contudo, para o ano agrícola de 2015/16, os efeitos positivos sobre AP e AIE proporcionados pela inoculação em 2013/14 não se confirmaram, sem aumento destes atributos morfológicos das plantas promovidos pela presença destas bactérias promotoras de crescimento. Para o diâmetro do colmo (DC) e o comprimento de espiga (CE) do milho não houve efeito da inoculação por A. brasilense em 2013/14 (Tabela 1). Porém, em 2015/16, a inoculação do milho promoveu efeito negativo apenas para o DC, o que resultou em valores inferiores aos encontrados nas plantas não inoculadas, diferentemente do constatado por Kappes et al. (2013), em que não foram constatadas diferenças positivas para inoculação no diâmetro do colmo.

O aumento do diâmetro de colmo é importante, pois esta característica morfológica é uma das que mais tem sido relacionada com o percentual de acamamento ou quebramento de planta na cultura do milho. Além disso, o diâmetro de colmo é importante para a obtenção de alta produtividade, pois quanto maior o seu diâmetro, maior a capacidade da planta em armazenar fotoassimilados que contribuirão com o enchimento dos grãos (Cruz, et al., 2008; Lana, et al., 2009).

Tabela 1 - Médias de altura de plantas (AP), altura de inserção da primeira espiga (AIE), diâmetro do colmo (DC) e comprimento de espiga (CE) de milho consorciado com U. brizantha cv. Marandu, em função da inoculação ou não com A. brasilense e adubação fosfatada residual, nos anos agrícolas 2013/14 e 2015/16. Selvíria-MS.

\begin{tabular}{|c|c|c|c|c|c|c|c|c|}
\hline \multirow{3}{*}{ TRATAMENTOS } & \multicolumn{2}{|c|}{ AP } & \multicolumn{2}{|c|}{ AIE } & \multicolumn{2}{|c|}{$\mathrm{DC}$} & \multicolumn{2}{|c|}{$\mathrm{CE}$} \\
\hline & $2013 / 14$ & $2015 / 16$ & $2013 / 14$ & $2015 / 16$ & $2013 / 14$ & $2015 / 16$ & $2013 / 14$ & $2015 / 16$ \\
\hline & \multicolumn{8}{|c|}{--------------------------- cm -------------------------- } \\
\hline \multicolumn{9}{|l|}{ Inoculação (I) } \\
\hline Sem & $254 \mathrm{~b}$ & 212 & $121 \mathrm{~b}$ & 113 & 1,95 & $2,29 \mathrm{a}$ & 18,5 & 17,1 \\
\hline Com & $258 \mathrm{a}$ & 211 & $125 \mathrm{a}$ & 113 & 2,02 & $2,07 \mathrm{~b}$ & 18,4 & 17,4 \\
\hline DMS & 3,05 & 4,62 & 2,28 & 3,41 & 0,07 & 0,10 & 0,80 & 0,50 \\
\hline \multicolumn{9}{|l|}{ Doses de $\mathrm{P}_{2} \mathrm{O}_{5}(\mathrm{D})$} \\
\hline 0 & 255 & 210 & 122 & 111 & 2,01 & 2,17 & 18,1 & 17,3 \\
\hline 30 & 257 & 210 & 126 & 114 & 1,94 & 2,18 & 18,3 & 16,9 \\
\hline 60 & 254 & 212 & 123 & 112 & 1,96 & 2,18 & 18,6 & 17,3 \\
\hline 120 & 257 & 212 & 123 & 113 & 2,00 & 2,17 & 18,6 & 17,6 \\
\hline 240 & 256 & 213 & 123 & 115 & 2,02 & 2,19 & 18,4 & 17,3 \\
\hline & \multicolumn{8}{|c|}{ Teste F } \\
\hline Teste F (I) & $5,27 *$ & $0,24^{\mathrm{ns}}$ & $9,77 *$ & $0,02^{\mathrm{ns}}$ & $3,56^{\mathrm{ns}}$ & $20,23^{* * *}$ & $0,10^{\mathrm{ns}}$ & $1,13^{\mathrm{ns}}$ \\
\hline Teste F (D) & $0,66^{\mathrm{ns}}$ & $0,25^{\mathrm{ns}}$ & $1,39^{\mathrm{ns}}$ & $0,61^{\mathrm{ns}}$ & $0,69^{\text {ns }}$ & $0,03^{\mathrm{ns}}$ & $0,22^{\mathrm{ns}}$ & $0,66^{\mathrm{ns}}$ \\
\hline Modelo de equação & - & - & - & - & - & - & - & - \\
\hline $\mathrm{R}^{2}$ & - & - & - & - & - & - & - & - \\
\hline Teste F (I x D) & $2,10^{\mathrm{ns}}$ & $0,46^{\mathrm{ns}}$ & $1,60^{\mathrm{ns}}$ & $0,81^{\mathrm{ns}}$ & $0,74^{\mathrm{ns}}$ & $0,55^{\mathrm{ns}}$ & $0,13^{\mathrm{ns}}$ & $1,57^{\mathrm{ns}}$ \\
\hline $\mathrm{CV}(\%)$ & 1,84 & 3,38 & 2,85 & 4,68 & 5,20 & 7,09 & 6,68 & 4,48 \\
\hline
\end{tabular}

Médias seguidas por mesma letra na coluna, para diferentes tratamentos, não diferem entre si pelo teste t a $5 \%$ de probabilidade. $* *$ e $*$ : significativo a 1 e $5 \%$ de probabilidade pelo Teste F, respectivamente. ns não significativo. Em que: DMS: diferença mínima significativa e CV: coeficiente de variação. Fonte: Autores.

Os ganhos verificados em alguns atributos morfológicos, independentemente do ano agrícola, podem ser atribuídos aos resultados positivos das associações de bactérias diazotróficas e a cultura do milho em termos de potencial agronômico, fixação de nitrogênio e/ou promoção do crescimento. No entanto, para que isso ocorra de forma satisfatória é imprescindível a combinação de muitos fatores bióticos e ambientais, tais como genótipo da planta, comunidade microbiológica do solo e disponibilidade de nitrogênio (Roesch, et al., 2006). Assim, Barassi et al. (2008) relataram que a melhoria em parâmetros fotossintéticos das folhas no potencial hídrico, incrementando o teor de água do apoplasto e maior elasticidade da parede celular, podem aumentar a produção de biomassa e consequentemente a AP e o DC, como aqui verificados. 
Quanto ao fornecimento de P residual por meio de aplicações crescentes de $\mathrm{P} 2 \mathrm{O} 5$ na aveia preta antecessora ao milho, não promoveu alterações nos atributos morfológicos AP, AIE, DC e CE, em ambos os anos agrícolas (Tabela 1). A ausência de alterações nos atributos mesmo entre as maiores doses (120 e $240 \mathrm{~kg}$ ha-1) e a testemunha (sem o fornecimento de P) pode estar associado ao médio teor de $\mathrm{P}$ disponível nos solos da área experimental (25 e 19 mg dm³ em 2013/14 e 2015/16, respectivamente). Associado a isto, o fato destas aplicações terem sido realizadas na cultura antecessora, no caso a aveia preta, pode ter contribuído para a ausência de efeitos significativos do incremento de P, pelo efeito da liberação do nutriente da palhada da aveia preta antecessora aos dois cultivos de milho.

A inoculação com A. brasilense, bem como as aplicações de P2O5 não alteraram significativamente o diâmetro da espiga (DE) e o número de espigas (NE) em ambos os anos agrícolas (Tabela 2). A presença do A. brasilense não proporcionou aumento no número de plantas (NP) cultivadas por hectare em ambos os anos agrícolas (Tabela 2). Tanto em 2013/14, quanto em 2015/16, o NP das áreas inoculadas foi estatisticamente inferior ao registrado para as áreas não inoculadas.

$\mathrm{O}$ estande de plantas de milho é fundamental, pois exerce reflexos diretos na produtividade da cultura e, também, na produção de massa seca (Crusciol et al., 2010). Esse componente está relacionado ao DC, e espera-se que o maior fornecimento de água e nutrientes proporcione maior porte de plantas, consequentemente um maior estande final, entretanto, tal resultado não foi constatado na presente pesquisa.

Os menores valores médios obtidos para massa seca de plantas (MSP) em plantas inoculadas, com as bactérias diazotróficas, na safra 2013/14, podem estar associados ao menor número final de plantas por hectare do tratamento com inoculação no referido ano agrícola (Tabela 2), pois houve redução no NP inoculadas em comparação às não inoculadas.

Contudo, a hipótese mais provável é que os resultados estejam relacionados as condições edafoclimáticas da região durante a condução do experimento, do que propriamente ao efeito negativo do A. brasilense sobre as plantas, resultando assim, numa menor população final de plantas com consequente redução da massa destas plantas por unidade de área. Reis (2007) cita a interação positiva entre a inoculação e a cultura do milho, porém apresenta as dificuldades na utilização desta tecnologia a campo, em que, o principal gargalo à utilização do Azospirillum no milho tem sido a inconsistência dos resultados de pesquisas, que podem variar de acordo com a cultivar e/ou híbrido; as condições edafoclimáticas (Bartchechen, et al., 2010); devido a competição dessas bactérias diazotróficas com estirpes nativas; e às condições heterogêneas dos solos nos quais a bactéria é exposta. 
Tabela 2 - Médias de diâmetro de espiga (DE), número de espigas (NE), população de plantas (POP) de milho consorciado com U. brizantha cv. Marandu, em função da inoculação ou não com A. brasilense e adubação fosfatada residual, nos anos agrícolas 2013/14 e 2015/16. Selvíria-MS.

\begin{tabular}{|c|c|c|c|c|c|c|}
\hline \multirow{3}{*}{ TRATAMENTOS } & \multicolumn{2}{|c|}{$\mathrm{DE}$} & \multicolumn{2}{|c|}{$\mathrm{NE}$} & \multicolumn{2}{|c|}{ POP } \\
\hline & $2013 / 14$ & $2015 / 16$ & $2013 / 14$ & $2015 / 16$ & $2013 / 14$ & $2015 / 16$ \\
\hline & \multicolumn{2}{|c|}{$\mathrm{Cm}$} & \multicolumn{4}{|c|}{ - } \\
\hline \multicolumn{7}{|l|}{ Inoculação (I) } \\
\hline Sem & 4,79 & 4,60 & 55.264 & 61.437 & $55.278 \mathrm{a}$ & $59.419 \mathrm{a}$ \\
\hline Com & 4,74 & 4,60 & 54.604 & 59.666 & $52.431 b$ & $55.166 \mathrm{~b}$ \\
\hline DMS & 0,10 & 0,06 & 2.132 & 3.077 & 2.088 & 3.171 \\
\hline \multicolumn{7}{|l|}{ Doses de $\mathrm{P}_{2} \mathrm{O}_{5}(\mathrm{D})$} \\
\hline 0 & 4,72 & 4,63 & 53.021 & 62.500 & 53.299 & 59.329 \\
\hline 30 & 4,74 & 4,61 & 54.253 & 59.947 & 53.004 & 55.729 \\
\hline 60 & 4,75 & 4,59 & 54.722 & 61.041 & 53.316 & 57.708 \\
\hline 120 & 4,80 & 4,60 & 57.708 & 59.270 & 55.486 & 56.822 \\
\hline 240 & 4,80 & 4,57 & 54.965 & 60.000 & 54.167 & 56.875 \\
\hline \multicolumn{7}{|c|}{ Teste F } \\
\hline Teste F (I) & $1,18^{\mathrm{ns}}$ & $0,02^{\mathrm{ns}}$ & $0,40^{\mathrm{ns}}$ & $1,38^{\mathrm{ns}}$ & $7,83^{* *}$ & $7,50^{*}$ \\
\hline Teste F (D) & $0,44^{\mathrm{ns}}$ & $0,58^{\mathrm{ns}}$ & $2,20^{\mathrm{ns}}$ & $0,55^{\mathrm{ns}}$ & $0,79^{\mathrm{ns}}$ & $0,60^{\mathrm{ns}}$ \\
\hline Modelo de equação & - & - & - & - & - & - \\
\hline $\mathrm{R}^{2}$ & - & - & - & - & - & - \\
\hline Teste F (I x D) & $0,12^{\text {ns }}$ & $1,12^{\text {ns }}$ & $3,47^{*}$ & $0,71^{\mathrm{ns}}$ & $2,05^{\mathrm{ns}}$ & $0,30^{\mathrm{ns}}$ \\
\hline $\mathrm{CV}(\%)$ & 3,21 & 2,09 & 5,98 & 7,87 & 5,98 & 8,57 \\
\hline
\end{tabular}

Médias seguidas por mesma letra na coluna, para diferentes tratamentos, não diferem entre si pelo teste $\mathrm{t}$ a $5 \%$ de probabilidade. $* *$ e $*$ : significativo a 1 e $5 \%$ de probabilidade pelo Teste F, respectivamente. ns não significativo. Em que: DMS: diferença mínima significativa e CV: coeficiente de variação. Fonte: Autores.

A combinação dos tratamentos inoculação ou não com aplicação de $\mathrm{P}_{2} \mathrm{O}_{5}$ residual promoveu alterações no número de espiga (NE) em 2013/14, resultado este que não se confirmou em 2015/16 (Tabela 2). No desdobramento da interação entre inoculação e doses residuais de $\mathrm{P}_{2} \mathrm{O}_{5}$ (Tabela 3) para o número de espigas de milho, constatou-se diferenças entre os tratamentos com A. brasilense somente para a dose de $60 \mathrm{~kg} \mathrm{ha}^{-1} \mathrm{P}_{2} \mathrm{O}_{5}$. Assim, as plantas oriundas de sementes não inoculadas, e que foram submetidas ao efeito residual do $\mathrm{P}$, apresentaram valores médios superiores às plantas inoculadas. No entanto, a aplicação crescente de $\mathrm{P}_{2} \mathrm{O}_{5}$ na aveia preta não influenciou no número de espigas de milho da área, não havendo assim, ajuste de regressão para os resultados.

Tabela 3- Desdobramento da interação inoculação com A. brasilense e adubação fosfatada residual para número de espigas (NE) e massa seca das plantas de milho no ano agrícola 2013/14, e da massa seca das plantas de milho do ano agrícola 2015/16. Selvíria-MS.

\begin{tabular}{|c|c|c|c|c|c|c|c|}
\hline \multirow{2}{*}{ Inoculação } & \multicolumn{5}{|c|}{ Doses de $\mathrm{P}_{2} \mathrm{O}_{5}\left(\mathrm{~kg} \mathrm{ha}^{-1}\right)$} & \multirow{2}{*}{ Equação } & \multirow{2}{*}{$\mathrm{R}^{2}$} \\
\hline & 0 & 30 & 60 & 120 & 240 & & \\
\hline \multicolumn{8}{|c|}{$\operatorname{NE}\left(n^{\circ}\right)-2013 / 14$} \\
\hline Sem & $53.750 \mathrm{a}$ & $53.333 a$ & $58.611 \mathrm{a}$ & $56.111 \mathrm{a}$ & $54.514 \mathrm{a}$ & - & $\mathrm{ns}$ \\
\hline Com & $53.292 \mathrm{a}$ & $55.174 a$ & $50.833 b$ & $53.306 a$ & $55.417 \mathrm{a}$ & - & ns \\
\hline
\end{tabular}

Médias seguidas pela mesma letra na coluna, não diferem entre si pelo teste $\mathrm{t}$ a $5 \%$ de probabilidade. $* *$ e $*$ : significativo a 1 e $5 \%$ respectivamente. ${ }^{\text {ns: }}$ não significativo. S: sem inoculação e C: com inoculação. Fonte: Autores.

Um dos fatores para a ausência de resposta ao incremento de $\mathrm{P}_{2} \mathrm{O}_{5}$ e seu efeito residual pode estar no teor médio inicial constatado no solo da área experimental em ambos os anos de cultivo, valor este considerado como adequado para o desenvolvimento do milho. Associado a isso, tem o fato da ciclagem de nutrientes a partir dos restos vegetais da cultura da aveia 
preta, o que pode ter incrementado maiores quantidades do nutriente ao solo, elevando seu teor a padrões considerados como suficientes para o estabelecimento e desenvolvimento das plantas do consórcio e produtividade do milho.

Para os componentes de produção, número de grãos por espiga (NFE), de grãos por fileira (NGF), de grãos por espiga (NGE), massa de 100 grãos e a produtividade de grãos do milho, não houve efeito significativo da inoculação com A. brasilense, bem como dos efeitos residuais de aplicação de $\mathrm{P}_{2} \mathrm{O}_{5}$, assim como a interação entre os tratamentos (Tabelas 4 e 5).

Tabela 4 - Médias do número de fileiras de grãos por espiga (NFE), número de grãos por fileira (NGF), número de grãos por espiga (NGE) e massa de grãos por espiga (MGE) do milho consorciado com U. brizantha cv. Marandu, em função da inoculação ou não com A. brasilense e adubação fosfatada residual, nos anos agrícolas 2013/14 e 2015/16. Selvíria-MS.

\begin{tabular}{|c|c|c|c|c|c|c|}
\hline \multirow{3}{*}{ TRATAMENTOS } & \multicolumn{2}{|c|}{ NFE } & \multicolumn{2}{|c|}{ NGF } & \multicolumn{2}{|c|}{ NGE } \\
\hline & $2013 / 14$ & $2015 / 16$ & $2013 / 14$ & $2015 / 16$ & $2013 / 14$ & $2015 / 16$ \\
\hline & \multicolumn{4}{|c|}{---------------- n no ---------------- } & \multicolumn{2}{|c|}{$\mathrm{g}$} \\
\hline \multicolumn{7}{|l|}{ Inoculação (I) } \\
\hline Sem & 15,5 & 15,4 & 35,8 & 32,7 & 559 & 502 \\
\hline Com & 15,0 & 15,1 & 36,1 & 33,1 & 539 & 498 \\
\hline DMS & 0,54 & 0,54 & 1,34 & 1,55 & 24,0 & 20,99 \\
\hline \multicolumn{7}{|l|}{ Doses de $\mathrm{P}_{2} \mathrm{O}_{5}(\mathrm{D})$} \\
\hline 0 & 15,3 & 15,0 & 35,8 & 32,8 & 548 & 494 \\
\hline 30 & 15,3 & 15,5 & 36,0 & 31,7 & 551 & 492 \\
\hline 60 & 15,0 & 15,1 & 36,3 & 33,9 & 553 & 509 \\
\hline 120 & 15,5 & 15,5 & 35,7 & 32,9 & 552 & 509 \\
\hline 240 & 15,1 & 15,0 & 35,9 & 33,1 & 541 & 495 \\
\hline \multicolumn{7}{|c|}{ Teste F } \\
\hline Teste F (I) & $3,31^{\mathrm{ns}}$ & $1,02^{\mathrm{ns}}$ & $0,22^{\mathrm{ns}}$ & $0,21^{\mathrm{ns}}$ & $2,89^{\text {ns }}$ & $0,17^{\mathrm{ns}}$ \\
\hline Teste F (D) & $0,35^{\mathrm{ns}}$ & $0,72^{\mathrm{ns}}$ & $0,10^{\text {ns }}$ & $0,83^{\text {ns }}$ & $0,16^{\mathrm{ns}}$ & $0,53^{\mathrm{ns}}$ \\
\hline Modelo de equação & - & - & - & - & - & - \\
\hline $\mathrm{R}^{2}$ & - & - & - & - & - & - \\
\hline Teste F (I x D) & $0,74^{\mathrm{ns}}$ & $0,80^{\mathrm{ns}}$ & $0,56^{\mathrm{ns}}$ & $1,76^{\mathrm{ns}}$ & $2,26^{\mathrm{ns}}$ & $2,67^{\mathrm{ns}}$ \\
\hline $\mathrm{CV}(\%)$ & 5,48 & 5,54 & 5,76 & 7,31 & 6,74 & 6,50 \\
\hline
\end{tabular}

Médias seguidas por mesma letra na coluna, para diferentes tratamentos, não diferem entre si pelo teste $\mathrm{t}$ a $5 \%$ de probabilidade. ** e *: significativo a 1 e $5 \%$ de probabilidade pelo Teste F, respectivamente. ns não significativo. Em que: DMS: diferença mínima significativa e CV: coeficiente de variação. Fonte: Autores.

A ausência de efeito da inoculação sobre a massa de 100 grãos, assim como para os demais componentes de produção foram decisivos para a não ocorrência de alterações na produtividade da cultura (Tabela 5). De acordo com Ohland et al. (2005), a massa de grãos por espiga é o componente de produção menos alterado pelas práticas de manejo e que, este componente é influenciado pelo genótipo, pela disponibilidade de nutrientes, além das condições climáticas estabelecidas durante os estádios de enchimento dos grãos. Nesse sentido, resultados positivos para esse importante componente de produção dependem primordialmente da absorção e assimilação de quantidades adequadas de nutrientes, dentre eles, o nitrogênio. Assim, a deficiência e/ou baixa disponibilidade deste nutriente no solo e consequentemente nos tecidos celulares da planta poderia proporcionar a formação de grãos com menor massa, fato este não ocorrente nos dois cultivos do milho em consórcio com o capim-marandu. 
Tabela 5 - Médias da massa de grãos por espiga (MGE), massa de 100 grãos (M100) e produtividade do milho consorciado com $U$. brizantha cv. Marandu, em função da inoculação ou não com A. brasilense e adubação fosfatada residual, nos anos agrícolas 2013/14 e 2015/16. Selvíria-MS.

\begin{tabular}{|c|c|c|c|c|c|c|}
\hline \multirow{3}{*}{ TRATAMENTOS } & \multicolumn{2}{|c|}{ MGE } & \multicolumn{2}{|c|}{ M100 } & \multicolumn{2}{|c|}{ PROD } \\
\hline & $2013 / 14$ & $2015 / 16$ & $2013 / 14$ & $2015 / 16$ & $2013 / 14$ & $2015 / 16$ \\
\hline & \multicolumn{4}{|c|}{----------------- g ----------------- } & \multicolumn{2}{|c|}{$\left(\mathrm{kg} \mathrm{ha}^{-1}\right)$} \\
\hline \multicolumn{7}{|l|}{ Inoculação (I) } \\
\hline Sem & 169,9 & 146,4 & 30,8 & 29,2 & 6.627 & 6.490 \\
\hline Com & 166,7 & 144,9 & 31,2 & 29,1 & 6.287 & 5.854 \\
\hline DMS & 8,54 & 8,34 & 1,33 & 0,86 & 472,0 & 686,0 \\
\hline \multicolumn{7}{|l|}{ Doses de $\mathrm{P}_{2} \mathrm{O}_{5}(\mathrm{D})$} \\
\hline 0 & 163,7 & 147,1 & 30,1 & 29,7 & 6.164 & 6.148 \\
\hline 30 & 168,6 & 140,9 & 30,86 & 28,8 & 6.369 & 6.000 \\
\hline 60 & 170,7 & 147,7 & 31,4 & 29,0 & 6.666 & 6.414 \\
\hline 120 & 172,7 & 148,2 & 31,9 & 29,1 & 6.638 & 6.064 \\
\hline 240 & 165,5 & 144,4 & 30,9 & 29,2 & 6.450 & 6.230 \\
\hline \multicolumn{7}{|c|}{ Teste F } \\
\hline Teste F (I) & $0,61^{\mathrm{ns}}$ & $0,13^{\text {ns }}$ & $0,39^{\text {ns }}$ & $0,12^{\text {ns }}$ & $2,19^{\text {ns }}$ & $3,57^{\mathrm{ns}}$ \\
\hline Teste F (D) & $0,63^{\mathrm{ns}}$ & $0,45^{\mathrm{ns}}$ & $0,84^{\mathrm{ns}}$ & $0,54^{\mathrm{ns}}$ & $0,64^{\mathrm{ns}}$ & $0,18^{\mathrm{ns}}$ \\
\hline Modelo de equação & - & - & - & - & - & - \\
\hline $\mathrm{R}^{2}$ & - & - & - & - & - & - \\
\hline Teste F (I x D) & $1,98^{\mathrm{ns}}$ & $1,62^{\text {ns }}$ & $0,72^{\mathrm{ns}}$ & $1,22^{\mathrm{ns}}$ & $1,14^{\mathrm{ns}}$ & $0,04^{\mathrm{ns}}$ \\
\hline $\mathrm{CV}(\%)$ & 7,82 & 8,87 & 6,63 & 4,57 & 11,26 & 17,22 \\
\hline
\end{tabular}

Médias seguidas por mesma letra na coluna, para diferentes tratamentos, não diferem entre si pelo teste $\mathrm{t}$ a $5 \%$ de probabilidade. $* *$ e $*$ : significativo a 1 e $5 \%$ de probabilidade pelo Teste F, respectivamente. ns não significativo. Em que: DMS: diferença mínima significativa e CV: coeficiente de variação. Fonte: Autores.

Cabe destacar também que, segundo Hungria (2011), outro fator a ser considerado é que certas gramíneas, como as braquiárias, em cultivos sucessivos podem ser hospedeiras de bactérias diazotróficas nativas do solo, e pelo histórico da área de 2 anos de pastagem anterior ao feijoeiro de inverno, aveia preta e depois o consórcio do milho com capim-marandu, podem justificar esta ausência de resposta da inoculação do milho.

Deste modo, a presença das bactérias nas condições da presente pesquisa não foi suficiente para incrementar a produtividade de grãos. A ausência de resposta encontrada corrobora com os resultados obtidos por Bartchechen et al. (2010) e Domingues Neto et al. (2013), que avaliando o efeito da inoculação de A. brasilense sobre os componentes de produção e produtividade do milho também não verificaram o efeito da inoculação. No caso do trabalho de Bartchechen et al. (2010), em estudo com inoculante comercial a base de A. brasilense combinado com doses de $\mathrm{N}$, a inoculação proporcionou resultados de produtividade superiores estatisticamente em relação a testemunha, no entanto, os autores não detectaram diferenças na produtividade com a inoculação isolada ou combinada à adubação nitrogenada de cobertura. Enquanto que no estudo de Domingues Neto et al. (2013), o uso de A. brasilense elevou a produção de biomassa da parte aérea e raízes, promovendo maior área de solo explorado, mas, não aumentou a produtividade de grãos do milho. Entretanto, Lana et al. (2012), na região oeste do Paraná, confirmaram os efeitos benéficos da inoculação constatando incrementos de 7 a $15 \%$ na produtividade do milho em função da inoculação com A. brasilense.

A resposta positiva das plantas à inoculação com bactérias diazotróficas pode ser atribuída a diversos fatores, além da síntese de substâncias promotoras do crescimento, dentre os quais, citam-se a alteração da atividade metabólica por meio de efeitos sobre as membranas celulares e proteção contra fitopatógenos (Bashan, et al., 2004). Também, a presença da bactéria pode favorecer uma maior solubilização de fosfatos e promover aumento na resistência das plantas ao estresse (Gray \& Smith, 2005). 
Existe grande divergência quanto a eficiência do uso do A. brasilense, uma vez que há estudos com respostas positivas ao uso da inoculação ou sem respostas significativas, como no presente estudo. Essas divergências de resposta podem estar associadas às diferentes condições de cultivo (Novakowiski, et al. 2011) em função destas bactérias estarem associadas livremente à planta, seja na rizosfera ou no interior dos tecidos, tornando-se muito susceptíveis ao ambiente (Gyaneshwar, et al., 2002). No entanto, outro fator que pode contribuir para as diferentes respostas à inoculação é o híbrido utilizado, pois alguns híbridos são mais responsivos à inoculação do que outros (Pereira, et al., 2019).

O efeito residual das doses de $\mathrm{P}_{2} \mathrm{O}_{5}$ sobre o desenvolvimento e produtividade da cultura do milho em consórcio com a $U$. brizantha cv. Marandu não exibiu ajustes significativos para nenhum atributo avaliado (Tabelas 4 e 5). Esses resultados são importantes visto que, por meio deles, se pode observar que o residual do $\mathrm{P}$ aplicado na cultura antecessora (aveia preta), não resultou em melhorias para as características agronômicas analisadas e produtividade do milho. Uma das hipóteses é o teor médio de P no solo que atrelado à ciclagem promovida pela palhada da aveia preta pode ter sido suficiente para nutrição do milho do consórcio em sucessão.

Em contrapartida, Harger et al. (2007) verificaram que para a produção de matéria seca da parte aérea da cultura do milho, a partir da fonte superfosfato triplo, todas as doses diferiram estatisticamente da testemunha, e os dados obtidos se ajustaram a uma função quadrática. Neste caso a produção máxima foi obtida com a dose de $131 \mathrm{~kg} \mathrm{ha}^{-1}$ de $\mathrm{P}_{2} \mathrm{O}_{5}$. No entanto, vale ressaltar que as diferenças de resultados entre os trabalhos são devido ao manejo aplicado a cultura e ao teor inicial de P no solo, pois, no presente estudo, avaliou-se apenas o efeito residual da adubação fosfatada e não seu efeito direto sobre a cultura do milho, numa área com histórico de SPD consolidada, com mais de 10 anos.

Cabe ressaltar que mesmo não havendo diferenças significativas no ano de 2013/14 (Tabela 6), o capim do consórcio em que o milho foi inoculado exibiram, em média, $669 \mathrm{~kg} \mathrm{ha}^{-1}$ a mais de matéria seca, valor esse que pode ser considerável para o ganho e rentabilidade do produtor rural. Ganho este que se maximiza se considerar que os animais terão $669 \mathrm{~kg}$ de forragem com 15\% a mais de proteína para consumo. Enquanto que no ano de 2015/16, a aplicação de A. brasilense nas sementes do milho do consórcio incrementou a produção de MS do capim Marandu em consórcio. 
Tabela 6 - Produção de massa seca da forrageira (MSF) no $1^{\circ}$ corte e $2^{\circ}$ das plantas de $U$. brizantha cv. Marandu, em função da inoculação ou não com A. brasilense no milho do consórcio e adubação fosfatada residual, nos anos agrícolas 2013/14 e 2015/16. Selvíria-MS.

\begin{tabular}{|c|c|c|c|c|}
\hline \multirow{3}{*}{ TRATAMENTOS } & \multicolumn{2}{|c|}{ MSF1 } & \multicolumn{2}{|c|}{ MSF2 } \\
\hline & $2013 / 14$ & $2015 / 16$ & $2013 / 14$ & $2015 / 16$ \\
\hline & \multicolumn{4}{|c|}{ 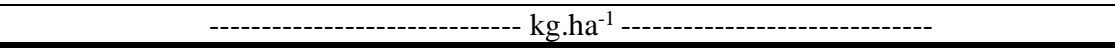 } \\
\hline \multicolumn{5}{|l|}{ Inoculação (I) } \\
\hline Sem & 4.806 & $2.892 b$ & 10.978 & $5.906 b$ \\
\hline Com & 5.475 & $3.983 \mathrm{a}$ & 12.625 & $8.769 a$ \\
\hline DMS & 695,5 & 580,13 & 1.903 & 1.047 \\
\hline \multicolumn{5}{|l|}{ Doses de $\mathrm{P}_{2} \mathrm{O}_{5}(\mathrm{D})$} \\
\hline 0 & 5.654 & 3.320 & 11.585 & 7.041 \\
\hline 30 & 5.432 & 3.407 & 12.036 & 7.343 \\
\hline 60 & 4.497 & 3.620 & 10.730 & 7.263 \\
\hline 120 & 5.056 & 3.517 & 11.461 & 7.920 \\
\hline 240 & 5.038 & 3.323 & 13.196 & 7.119 \\
\hline \multicolumn{5}{|c|}{ Teste F } \\
\hline Teste F (I) & $3,78^{\mathrm{ns}}$ & $14,89^{* *}$ & $3,15^{\mathrm{ns}}$ & $31,45^{* *}$ \\
\hline Teste F (D) & $1,36^{\mathrm{ns}}$ & $0,17^{\mathrm{ns}}$ & $0,78^{\mathrm{ns}}$ & $0,37^{\mathrm{ns}}$ \\
\hline Modelo de equação & - & - & - & - \\
\hline $\mathrm{R}^{2}$ & - & - & - & - \\
\hline Teste F (I x D) & $0,15^{\mathrm{ns}}$ & $1,39^{\mathrm{ns}}$ & $0,73^{\mathrm{ns}}$ & $2,20^{\mathrm{ns}}$ \\
\hline $\mathrm{CV}(\%)$ & 20,88 & 26,01 & 24,85 & 22,00 \\
\hline
\end{tabular}

Médias seguidas por mesma letra na coluna, para diferentes tratamentos, não diferem entre si pelo teste t a 5\% de probabilidade. ** e *: significativo a 1 e $5 \%$ de probabilidade pelo Teste F, respectivamente. ns não significativo. Em que: DMS: diferença mínima significativa e CV: coeficiente de variação. Fonte: Autores.

No primeiro ano de cultivo (2013/14) houve maior produção de matéria seca do capim quando comparado ao segundo ano (2015/16), porém sem respostas a inoculação (Tabela 6).

Decorridos 60 dias de vedação (após a colheita do milho) foi realizada uma nova avaliação do desenvolvimento da parte aérea da $U$. brizantha cv. Marandu. Assim como ocorreu no primeiro corte das plantas de U. brizantha, na segunda avalição da forrageira não houve alterações em sua produção de matéria seca em função da utilização do A. brasilense no primeiro ano de cultivo (Tabela 6). Contudo, este comportamento não se confirmou para o segundo ano (2015/16), sendo possível constatar efeitos significativos da aplicação da bactéria no milho, o que proporcionou incremento na matéria seca do capim advindo da área com o milho inoculado.

A ausência de efeitos significativos e positivos à inoculação em 2013/14 pode ser devido ao período compreendido entre a semeadura e o momento da avaliação. Por não haver adubação de base na semeadura da forrageira, é possível que o desenvolvimento inicial tenha sido mais lento, sendo potencializado gradativamente pela menor pluviosidade neste período (Figura 1), o que proporcionou efeitos significativos somente a partir do segundo ano de cultivo, com maior quantidade de chuvas acumuladas (Figura 1).

Mesmo não havendo diferenças estatísticas no primeiro ano de cultivo, a produção de palhada esteve dentro do recomendado por Bayer et al., (2000), que sugere um adicional de 10.000 a $12.000 \mathrm{~kg} \mathrm{ha}^{-1}$ por ano de matéria seca para manutenção do SPD. Logo, em 2015/16, houve uma queda na produtividade de palhada, possivelmente pelas condições climáticas (Figura 1) que favoreceu a velocidade na decomposição dos resíduos vegetais, e a aplicação de P somente em 2013, elemento essencial para o desenvolvimento das raízes que auxilia na maior absorção de água e nutrientes pelas plantas em sucessão. Além disso, não foram verificados efeitos das aplicações residuais de P sobre o incremento da massa seca das plantas da $U$. brinzantha $\mathrm{cv}$. Marandu, resultados estes que diferem dos relatados por Ieiri et al. (2010), que estudando fontes, doses e modos de aplicação de $\mathrm{P}$ constaram que doses crescentes promoveram o incremento na produção da matéria seca da forrageira U. decumbens Stapf. 
No entanto, os resultados encontrados neste estudo corroboram as observações relatadas por Oliveira et al. (2017) que não verificaram efeitos positivos do incremento de $\mathrm{P}$ no acréscimo da produção de matéria seca $U$. brizantha cv. Marandu. A ausência de resposta da adubação fosfatada na produção de massa seca do capim-marandu, pode ser justificada por forrageiras do gênero Urochloa aumentar a atividade da fosfatase ácida, e com isso, ampliar a mobilização de formas menos disponíveis de fósforo no solo (Calonego \& Rosolem, 2013; Janegitz, et al., 2013; Rosolem, et al.,2014).

De forma geral, as médias obtidas para massa seca da forrageira nos dois anos de cultivo, independente do tratamento, são consideradas como satisfatórias para uso em pastejo (acima de $2.500 \mathrm{~kg} \mathrm{ha}^{-1}$ ) de acordo com Pariz et al. (2011), em que avaliaram quatro espécies de braquiárias consorciadas na linha e a lanço no momento da semeadura do milho.

Desta maneira, pode-se inferir que a ausência de resposta na produção de grãos de milho e matéria seca do capimmarandu decorrente do residual da adubação fosfatada pode estar relacionada com a fertilidade do solo da área experimental (teores médios de P), e influência da forrageira na disponibilidade de P no solo, até mesmo para as áreas do tratamento testemunha (sem aplicação de $\mathrm{P}_{2} \mathrm{O}_{5}$ ), o que reduz os prováveis efeitos positivos da adubação fosfatada.

\section{Conclusão}

- A inoculação das sementes de milho por A. brasilense e a adubação fosfatada residual não resultaram em efeitos positivos sobre o crescimento, componentes da produção e produtividade de grãos de milho consorciado com capim-marandu.

- O capim-marandu foi beneficiado pela inoculação, nas sementes de milho, produzindo maior massa de parte aérea em áreas inoculadas com A. brasilense.

\section{Referências}

Barassi, C. A., Sueldo, R. J., Creus, C. M., Carrozzi, L. E., Casanovas, W. M. \& Pereyra, M. A. (2008). Potencialidad de Azospirillum en optimizer el crecimiento vegetal bajo condiciones adversas. In: Cassán, F.D., Garcia De Salamone, I. (Ed.). Azospirillum spp.: cell physiology, plant interactions and agronomic research in Argentina. Argentina: Asociación Argentina de Microbiologia, 49-59.

Bartchechen, A., Fiori, C. C. L., Watanabe, S. H. \& Guarido, R. C. (2010). Efeito da inoculação de Azospirillum brasiliense na produtividade da cultura do milho (Zea mays L.). Campo Digital, 5(1), 56-59.

Bashan, Y., Holguin, G. \& Bashan, L. E. De. (2004). Azospirillum-plant relationships: physiological, molecular, agricultural, and environmental advances (19972003). Canadian Journal of Microbiology, 50(8), 521-577.

Batista, K., Duarte, A. P., Ceccon, G., De Maria, I. C., Cantarella, H. Acúmulo de matéria seca e de nutrientes em forrageiras consorciadas com milho safrinha em função da adubação nitrogenada. Pesquisa Agropecuária Brasileira, 46(10), 1154-1160, out. 2011.

Bayer, C., Mielniczuk, J., Amado, T. J. C., Martin Neto, L. \& Fernandes, S. (2000). Organic matter storage in a sandy clay loam Acrisol affected by tillage a cropping systems in southern Brazil. Soil and Tillage Research, 54(1-2), 101-109.

Bergamaschi, C. (2006). Ocorrência de bactérias diazotróficas associadas às raízes e colmos de cultivares de sorgo. 71 f. Dissertação (Mestrado em Microbiologia Agrícola) - Universidade Federal do Rio Grande do Sul.

Calonego, J. \& Rosolem, C. A. (2013). Phosphorus and potassium balance in a cornsoybean rotation under no-till and chiseling. Nutrient Cycling Agroecosystems, 96(1), 123-31.

Carvalho, A. M. De., Coser, T. R., Rein, T. A., Dantas, R. De A., Silva, R. R. \& Souza, K. W. (2015). Manejo de plantas de cobertura na floração e na maturação fisiológica s seu efeito na produtividade do milho. Pesquisa Agropecuária Brasileira, 50(7), 551-561.

Cavallet, L. E., Pessoa, A. C. Dos S., Helmich, J. J., Helmich, P. R. \& Ost, C. F. (2000). Produtividade do milho em resposta à aplicação de nitrogênio e inoculação das sementes com Azospirillum spp. Revista Brasileira de Engenharia Agrícola e Ambiental, 4(1), 129-132.

Chioderoli, C. A., Mello, L. M. M. De, Grigolli, P. J., Silva, J. O. Da R. \& Cesarin, A. L. (2010). Consorciação de braquiárias com milho outonal em plantio direto sob pivô central. Engenharia Agrícola, 30(6), 1101-1109.

Concenco, G., Ceccon, G., Fonseca, I. C., Leite, L. F., Schwerz, F. \& Correia, I. T. (2012). Weeds infestation in corn intercropped with forages at different planting densities. Planta Daninha, 30(4), 721-728.

Costa, R. R. G. F., Quirino, G. Da S. F., Naves, D. C. De F., Santos, C. B., Rocha, A. F. De S. (2015). Efficiency of inoculant with Azospirillum brasilense on the growth and yield of second-harvest maize. Pesquisa Agropecuária Tropical, 45(3), 304-311. 
Crusciol, C. A. C., Soratto, R. P., Borghi, É. \& Mateus, G. P. (2010). Benefits of integrating crops and tropical pastures as systems of production. Better Crops International, 94(1), 14-16.

Cruz, S. C. S., Pereira, F. R. S., Santos, J. R., Albuquerque, A. W. \& Pereira R. G. (2008). Adubação nitrogenada para o milho cultivado em sistema plantio direto, no Estado de Alagoas. Revista Brasileira de Engenharia Agrícola e Ambiental, 12(1), 62-68.

Domingues Neto, F. J., Yoshimi, F. K., Garcia, R. D., Domingues, M. C. S. (2014). Influência de Azospirillum brasilense no desenvolvimento vegetativo, produção de forragem e acúmulo de massa seca da aveia preta. Enciclopédia Biosfera, 10(18), 2013-2019.

Galindo, F. S. (2015). Desempenho agronômico do milho e do trigo em função da inoculação com Azospirillum brasilense e doses e fontes de nitrogênio. 150 f. Dissertação (Mestrado). Universidade Estadual Paulista. Faculdade de Engenharia de Ilha Solteira. Especialidade: Sistemas de Produção, Ilha Solteira, 2015.

Gasparini, L. L., Costa, T. S., Hungaro, O. A. L., Sznitowski, A. D. \&Vieira Filho, J. E. R. (2017). Sistemas integrados de produção agropecuária e inovação em gestão: estudos de casos no Mato Grosso. Instituto de Pesquisa Econômica Aplicada.

Gray, E. J., Smith, D. L. Intracellular and extracellular PGPR: commonalities and distinctions in the plant-bacterium signaling processes. Soil Biology and Biochemistry, 37(3), 395-412, 2005 .

Gyaneshwar, P., Kumar, G. N., Parekh, L. J. \& Poole, P. S. (2002). Role of soil microorganisms in improving P nutrition of plants. Plant Soil, $245(1), 83-93$.

Harger, N., Brito, O. R., Ralisch, R., Ortiz, R. F., Watanabe, S. T. (2007). Avaliação de fontes e doses de fósforo no crescimento inicial do milho. Semina: Ciências Agrárias, 28(1), 39- 44.

Hernandez, F. B. T., Lemos-Filho, M. A. F. \& Buzetti, S. (1995). Software HIDRISA e o balanço hídrico de Ilha Solteira. Ilha Solteira: UNESP/FEIS - Área de Hidráulica e Irrigação. 45 p. (Série Irrigação, 1).

Hungria, M.(2011). Inoculação com Azospirillum brasilense: inovação em rendimento a baixo custo. Londrina: EMBRAPA Soja, 2011. 19 p. (Documentos, 325).

Hungria, M., Mendes, I. C., Reis Junior, F. B. (2010). 20 perguntas e respostas sobre fixação biológica de nitrogênio. Planaltina: Embrapa-Cerrados, 2010. 19 p. (Documentos, 281).

Ieiri, A.Y., Lana, M. Q., Korndorfer, G. H. \& Pereira, H. S. (2010). Fontes, doses e modos de aplicação de fósforo na recuperação de pastagem com Urochloa. Ciência Agrotecnológica, 34(5), 1154-1160.

Janegitz, M. C., Inoue, B. S., Rosolem, C. A. (2013). Formas de fósforo no solo após o cultivo de braquiária e tremoço branco. Ciência Rural, 43, 1381-1386.

Kappes, C., Arf, O., Arf, M. V., Ferreira, J. P., Dal Bem, E. A., Portugal, J. R. \& Vilela, R. G. (2013). Inoculação de sementes com bactéria diazotrófica e aplicação de nitrogênio em cobertura e foliar em milho. Semina: Ciências Agrárias, 34(2), 527-538.

Lana, M. C., Dartora, J., Marini, D., Hann, J. E. H. (2012). Inoculation with Azospirillum, associated with nitrogen fertilization in maize. Revista Ceres, 59(3), $399-405$.

Lana, M. C., Woytichoski Júnior, P. P., Braccini, A. L., Scapim, C. A., Ávila, M. R. \& Albrecht, L. P. (2009). Arranjo espacial e adubação nitrogenada em cobertura na cultura do milho. Acta Scientiarum Agronomy, 31(3), 433-438.

Nascente, A. S. \& Crusciol, C. A. C. (2012). Cover crops and herbicide timing management on soybean yield under no-tillage system. Pesquisa Agropecuária Brasileira, 47, n. 2, p. 187-192.

Novakowiski, J. H., Sandini, I. E., Falbo, M. K., Moraes, A. De. \& Cheng, N. C. (2011). Efeito residual da adubação nitrogenada e inoculação de Azospirillum brasilense na cultura do milho. Semina: Ciências Agrárias, Londrina, 32(4), 1687-1698.

Ohland, R. A. A., Souza, L. C. F., Hernani, L. C., Marchetti, M. E. \& Gonçalves, M. C. (2005). Culturas de cobertura do solo e adubação nitrogenada no milho em plantio direto. Ciência e Agrotecnologia, 29(3), 538-544, 2005.

Oliveira, J. P. M. De., Oliveira Filho, L. C. I De. \& Pocojeski, E. (2017). Aplicação localizada de monoamônio fosfato favorece a disponibilidade de P no solo e sua absorção. Revista Scientia Agrária, 18(1), 12-19.

Pariz, C. M., Andreotti, M., Azenha, M. V., Bergamaschine, A. F., Mello, L. M. M. \& Lima, R. C. (2011). Produtividade de grãos de milho e massa seca de braquiárias em consórcio no sistema de integração lavoura-pecuária. Ciência Rural, 41(5), 875-882.

Pereira, L, C., Correria, L. V., Braccini, P. H. F., Matera, T. C., Pereira, R. C. \& Suzukawa, A. K. (2019). tratamento industrial e pré-inoculação do milho com Azospirillum spp.: potencial fisiológico das sementes e produtividade. Revista Brasileira de Milho e Sorgo, v.18, n.2, p. 245-256.

Reis Júnior, F. B., Machado, C. T. De T., Machado, A. T. \& Sodek, L. (2008) Inoculação de Azospirillum amazonense em dois genótipos de milho sob diferentes regimes de nitrogênio. Revista Brasileira de Ciência do Solo, 32, n. 3, p. 1139-1146.

Reis, M. (2007). Uso de bactérias fixadoras de nitrogênio como inoculante para aplicação em gramíneas. Seropédica: Embrapa Agrobiologia. 22 p. (Documentos, 232).

Roesch, L. F. W., Olivares, F. L., Passaglia, L. P. M., Selbach, P. A., Sá, E. L. S De. \& Camargo, F. A. O. (2006). Characterization of diazotrophic bacteria associated with maize: effect of plant genotype, ontogeny and nitrogen-supply. World Journal of Microbiology \& Biotechnology, 22(9), 967-974.

Rosolem, C. A., Merlin, A. \& Bull, J. C. L. (2014). Soil phosphorus dynamics as affected by congo grass and P fertilizer. Scientia Agricola, 71, $309-315$.

Sereia, R. C., Leite, L. F., Alves, B. \& Ceccon, G. (2012). Crescimento de Brachiaria spp. e milho safrinha em cultivo consorciado. Agrarian, 5(18), 349-355, 2012. 
Research, Society and Development, v. 11, n. 3, e9111326134, 2022

(CC BY 4.0) | ISSN 2525-3409 | DOI: http://dx.doi.org/10.33448/rsd-v11i3.26134

Tiecher, T., Calegarib, A., Canerc, L. \& Rheinheimerd, D. S. (2017). Soil fertility and nutrient budget after 23-years of different soil tillage systems and winter cover crops in a subtropical Oxisol. Geoderma, 308, 78-85.

Valderrama, M., Buzetti, S., Benett, C. G. S., Andreotti, M. \& Teixeira Filho, M. C. M. (2011). Fontes e doses de NPK em milho irrigado sob plantio direto. Pesquisa Agropecuaria Tropical, 41(2), 254-263. 